WellBeing International

WBI Studies Repository

2004

\title{
Medical Training Using Simulation: Toward Fewer Animals and Safer Patients
}

Jonathan Balcombe

Physicians Committee for Responsible Medicine

Follow this and additional works at: https://www.wellbeingintlstudiesrepository.org/acwp_arte

Part of the Bioethics and Medical Ethics Commons, Laboratory and Basic Science Research

Commons, and the Research Methods in Life Sciences Commons

\section{Recommended Citation}

Balcombe, J. (2004). Medical training using simulation: Toward fewer animals and safer patients. Altern Lab Anim, 32(S1): 553-560.

This material is brought to you for free and open access by WellBeing International. It has been accepted for inclusion by an authorized administrator of the WBI Studies Repository. For more information, please contact wbisr-info@wellbeingintl.org.

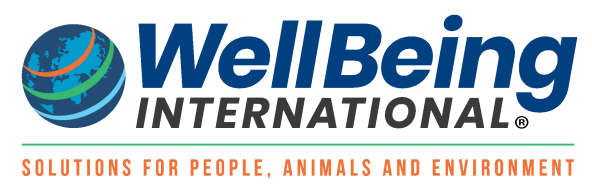




\title{
Medical Training Using Simulation: Toward Fewer Animals and Safer Patients
}

\author{
Jonathan Balcombe ${ }^{1}$ \\ Immersion Medical, Inc., 55 West Watkins Mill Road, Gaithersburg, MD 20878, USA \\ E-mail: pumilla@onetel.com
}

\begin{abstract}
Summary - This paper presents the current status of computer-based simulation in medicine. Recent technological advances have enabled this field to emerge from esoteric explorations in academic laboratories to commercially available simulators designed to train users to perform medical procedures from start to finish. Today, more than a dozen companies are producing virtual reality simulators and interactive manikins for training in endoscopy, laparoscopy, anaesthesia, trauma management, angiography, and needle insertion. For many of these procedures, thousands of animals are still being used in training. Yet simulation has many advantages that can transcend scientific, ethical, economic and logistical problems that arise when using animals. The first validation studies of medical simulators began appearing in the late 1990s, and the early results indicate that these devices measure what they are intended to, and that they can improve performance relative to traditional learning methods. In addition to expanded use for new and existing minimally invasive procedures, medical simulators will probably soon be used in physician credentialing, and they may someday allow surgeons to rehearse procedures in a patient-specific operating environment. Replacing animals with simulators in medical training is limited no longer by technical feasibility but by a willingness of the medical community to embrace it.
\end{abstract}

Key words: alternatives, animals, endoscopy, medical simulation, training, virtual reality.

\section{Introduction}

One of the most exciting applications of technology to the life sciences is the use of computer-based simulations to recreate experiences and processes. As simulation technology grows, so does its application to different fields of inquiry. Broad applications of simulation include modelling ecological processes, studying animal behaviour patterns (e.g. group motion in flocks and herds), plotting evolutionary trajectories, predicting genetic outcomes, and recreating medical procedures for training purposes.

Computer-based simulation is well suited to medical training, and recent technological advances have enabled the field to expand significantly since Coppa $\&$ Nachbar presented a paper on virtual reality in medicine at the Second World Congress, held in Utrecht in 1996 (1). In the USA, there is now an annual convention dedicated to the subject; an estimated 476 participants attended the 10th annual Medicine Meets Virtual Reality Program, held in San Diego, CA, in January 2002, where 239 presentations were given.

The purpose of this paper is to outline the current status and anticipated future trends for simulation in medical training and to relate this to animal use practices. Definitions of "simulation" vary. In the medical training arena, simulation has been defined to include such low-tech examples as the use of hollowed cantaloupes connected in series to simulate colonic anatomy for endoscopy training (2), and even the use of animals as a "simulation" of the human patient (3). In this paper, I use the term simulation to mean computer-based devices that simulate reality for the purpose of acquiring, maintaining and/or assessing medical knowledge and skills.

\section{Parallels with Aviation}

Medical training has many parallels to aviation training, which provided the impetus for the first computer-based training simulators. A brief summary of the parallels between simulation's benefits to aviation and medicine is instructive. Flying an aircraft, like performing surgery, demands precision in perceptual-motor skill, and it is a skill to which the safety and well-being of large numbers of people are entrusted on a daily basis. Today, the vast majority of commercial pilots are trained and at least partially certified by using aviation simulators. The three factors that probably account more than any others for the aviation industry's embracing of simulation are the same three factors that have made simulation so well-suited to medical training. 
1. Simulators are safe. It is possible to provide training in emergency and hazardous procedures with no fear of harm to the trainee or others (passengers in aviation; patients in medicine). Ethical considerations involved in training are minimised with the use of simulation.

2. Simulators are flexible. With the amount of computational power available in modern simulation systems, it is possible to provide users with a wide variety of training, rehearsal and certification scenarios and procedures in a relatively short period of time. It is also possible to use the capabilities of simulation systems (e.g. recordplayback, on-line performance measurement) to score human performance in these scenarios.

3. Simulators are cost-effective. Particularly when one considers the number of potential training scenarios that can be used, computer-based simulation provides a great deal of training for the investment. When simulators are used for aviation training, aircraft do not have to be taken out of primary service to accommodate training needs; medical simulators similarly reduce the amount of time needed for clinical training in the operating room, the endoscopy suite, or other facilities whose primary function is patient treatment. Simulators can also obviate the need for animals and human cadavers, whose costs are cumulative. Insurance companies have provided insurance premium discounts to both pilots and their employers trained and certified on flight simulators. This milestone was recently achieved for medical simulators when a Boston-area insurance firm began providing malpractice insurance discounts to providers trained on simulators.

Aviation simulation has surpassed a critical point when its value (both functional and economic) in aviation training is universally recognised, and its future assured for as long as humans wish to fly. This is significant to medical simulation, for it presages a similar outcome as exposure to and acceptance of the technology grows in the medical sector.

\section{Virtual Reality Simulators and Human Patient Simulators}

Today, computer-based medical training simulators fall under two broad categories: 1) virtual reality simulators (VRSs), and 2) interactive manikins, better known as human patient simulators (HPSs). These two categories can crudely be distinguished by their emphasis of the internal patient and the external patient, respectively, though there is much overlap in their functions and capabilities. A major thrust of VRS today is recreating minimally-invasive surgery
(MIS), a growing catalogue of diagnostic and therapeutic procedures that cause much less damage to body tissues than does traditional scalpel-based open surgery. MIS includes endoscopy (e.g. bronchoscopy, colonoscopy), laparoscopy (e.g. cholecystoscopy, arthroscopy), and endovascular interventions (e.g. coronary stenting, percutaneous transluminal coronary angioplasty [PTCA]). Although not technically classed as MIS, needle/catheter-based procedures (e.g. thoracentesis, central venous catheterisation) are also well-suited to simulation.

The psychomotor environment created by MIS procedures lends itself well to VRS training. A computer monitor can display what is seen on a video monitor during actual procedures, and the limited view afforded by MIS is more amenable to real time digital representation than is open surgery. For this reason, learning to recognise and respond to subtle tactile cues is particularly important in MIS. It is recreating these haptic (touch-based) experiences that presents perhaps the greatest challenge to effective simulation.

\section{Commercially Available Medical Simulators}

Just a decade ago, there were only two or three companies developing and producing medical simulation devices, and these were limited to computerenhanced manikins. Today, there are more than a dozen such companies. This growth is partially attributable to the rapid evolution in computer chip technology. Around 1997, that technology reached the point that the processing capabilities required of a virtual reality medical simulator could be delivered on a personal computer (PC). This development brought the cost of medical simulators within reach of the budgets of most medical teaching institutions.

The following list of medical simulation companies is not exhaustive, but it gives a sense of the current field.

\section{Virtual reality simulators}

- Immersion Medical (USA): endoscopy, endovascular, needle-based procedures.

— Simbionix (Israel): laparoscopy, endoscopy.

- Medical Simulation Corp. (USA): surgery suite for cardiac catheterisation, electrophysiology.

— Reachin Technologies (Sweden): laparoscopy.

— Surgical Science (Sweden): laparoscopy.

- Mentice Corp. (Sweden): arthroscopy, laparoscopy, cardiac catheterisation. 
- Xitact (Switzerland): laparoscopic cholecystectomy.

\section{Human patient simulators}

- Medical Education Technology Inc. (METI) (USA): "STAN" anaesthesiology, airway management, vital signs, drug interactions, etc.

- MedSim (Israel/USA): Ultrasound, Ob-Gyn exams.

- Laerdal Medical Corporation (Norway): "SimMan" airway management, trauma response, etc.

— Lockheed Martin (USA): "Martin" endoscopic nasal surgery.

— Simulab Corp. (USA): "TraumaMan" diagnostic peritoneal lavage, chest tube insertion, percardiocentesis, cricothyroidotomy, etc.

HPSs, or "digitally enhanced manikins" as they are sometimes referred to, typically consist of a human manikin animated with a variety of electromechanical or pneumatic devices producing respiratory movement, palpable pulses, heart and lung sounds, realistic airway anatomy, twitches and spasms and simulated body fluids (e.g. blood and urine). A system computer governs interactive mathematical models of drug function, metabolism, cardiac function, gas exchange and fluid balance. HPSs simulate many clinical scenarios and may provide vital signs, breath and heart sounds, arterial pulses, pupillary reactions to light and trauma, lungs that take in oxygen and exhale carbon dioxide and a tongue that swells. Users can learn how to recognise and treat reactions to an extensive library of drugs and to perform anaesthesia, intubation, chest tube insertion, needle decompression, pericardiocentesis and other interventions (4). HPSs are highly suitable for team training in a suite that recreates the patient care environment.

\section{Immersion Medical's AccuTouch Endoscopy Simulator}

A description of Immersion Medical's AccuTouch ${ }^{\circledR}$ Endoscopy Simulator for training in colonoscopy provides a good example of the current state-of-the-art. There are three colonoscopy modules on this platform: Introduction, Biopsy, and Basic Polypectomy. All operate on the same hardware device, which features a "manikin" with interchangeable anatomical reference plates (buttocks/anus for colonoscopy and flexible sigmoidoscopy; face for bronchoscopy and endoscopic retrograde cholangiopancreatography
[ERCP]), monitor for endoscopic views and didactics, a proxy endoscope and accessories (e.g. polypectomy snare handle; Figure 1). Didactic content includes videos and animations demonstrating relevant anatomy (embryologic, gross, endoscopic), an atlas of pathology images from real patients, indications and contraindications, pre- and post-procedural steps, complications associated with the procedure, live video segments and animations that instruct users in colonoscope features and handling, and procedural techniques and clinical pearls. Each module has six virtual patient cases presenting progressively difficult anatomy and pathologies (e.g. colitis, haemorrhoids, diverticulosis, polyps, and cancer). Associated user options include a "Virtual Attending" that provides tips and hints during a procedure, and an external view of the entire colon showing scope location and progress.

The proxy colonoscope has the look and feel of a real scope except that hydraulic and pneumatic functions in a real scope are controlled electronically (see Figure 1). Software simulates all scope functions during the procedure, including wheels to deflect the articulating scope tip, air insufflation, squirting water to clear the camera lens, suction, and a working channel through which proxy tools (e.g. biopsy forceps, polypectomy snare) can be inserted. The user inserts the colonoscope tip into the device and navigates the scope tube through the virtual lumen in real time. Software detects collisions between tools and anatomy, which deforms appropriately. The user also feels appropriate tactile resistance on the scope or working channel tool. Patient vital signs (pulse, respiration, blood pressure and oxygen levels) are displayed throughout the duration of the procedure. The anatomy expands with air insufflation and collapses with

\section{Figure 1: Immersion Medical's AccuTouch Endoscopy Simulator (colonoscopy module)}

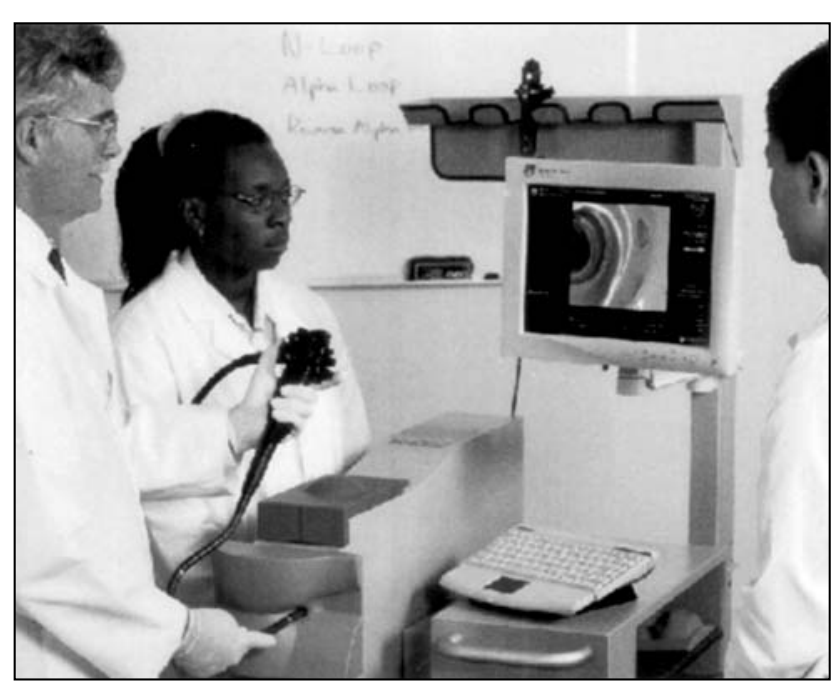


suction (or spontaneously, due to peristalsis). Complications can be preset by an instructor to occur spontaneously; others arise according to user performance. For example, the patient will respond audibly and variably to discomfort or pain, severing a polyp head without applying electrocautery will result in uncontrolled bleeding, and inappropriate use of sedative and counter-sedative is reflected in patient vital signs. As in the clinical setting, the user may take still images of pathology.

During each simulation session, the software tracks a broad range of metrics (a total of over 100) and presents the user with a report at the end of each colonic examination. Primary metrics include procedure duration, degree of patient discomfort, percentage of mucosa visualised, successful detection and response to pathology, and ability to perform retroflexion. These data are also tracked longitudinally, allowing users to monitor their progress over many trials.

\section{Medical Simulation and Animal Use}

Without question, medical simulation has the potential to replace the use of animals as human surrogates in medical training. The real questions are how much and how soon? Unfortunately, there are no current efforts to compile national animal use trends in the USA, so existing knowledge is based mainly on what the medical education community has to say.

Many of the procedures for which animals are still used in training can now be learned and practised on simulators. Both VRS and HPS cover many of the interventions taught in human trauma training, for which some 5000 dogs are still used yearly in the USA (5). These include diagnostic peritoneal lavage (DPL), endotracheal intubation, pericardiocentesis, cricothyroidotomy and defibrillation. Others, such as central venous catheterisation and thoracentesis, are being developed.

Similarly, where live anaesthetised pigs and dogs are still standard use for practising laparoscopy and endoscopy, there are now VRSs that reproduce many of these procedures with high fidelity. Simulated endoscopic procedures include bronchoscopy, sigmoidoscopy, colonoscopy, ureteroscopy, gastroscopy and ERCP, with hysteroscopy and endoscopic ultrasound under development. Among simulated laparoscopic procedures (inserted into the patient via keyhole-sized incisions) can be counted renal surgery, cholecystectomy, gynaecology and arthroscopy. Yet, in a 2002 survey by the European Research Centre for Alternatives (EURCA), ten out of ten responding institutions reported using animals (pigs and rabbits) in their laparoscopic/endoscopic training curricula.
While there is almost universal acceptance for the use of models and simulations in medical education, these tools are still widely viewed as adjuncts rather than alternatives. Prevalent opinion is that animals serve as an intermediate between models/simulators and clinical training with human patients. This thinking is based on the belief that simulators cannot yet provide either the realism or the range of scenarios that animals can.

Adherence to tradition is another factor keeping animals in the medical training picture. The use of animals to study human medicine has a history dating back to at least Roman times (6). Live anaesthetised animals and ex vivo preparations have been used in endoscopy training since endoscopic surgical techniques first appeared in the 1960s. Pigs and dogs are the most commonly used, and at least one study experimented with using a baboon for practising ERCP before concluding that cost and availability were too limited (7). Animal parts, usually procured from slaughterhouses, are also used. The Erlangen Active Simulator for Interventional Endoscopy (EASIE) uses visceral pig organs placed inside a plastic human-shaped torso. Perfusion with citrated pig blood creates arterial spurting, and polyps are created by purse-string suturing of the mucosa (8). The model is used to practise haemostasis, polypectomy, sphincterotomy, stent insertion and other endoscopic procedures. Owing to the preparation and planning required of EASIE, this model is not expected to gain in popularity, especially with the increasing competition from computer-based simulators for endoscopy training.

\section{Advantages of Simulation}

Traditional views aside, problems with the current medical training paradigm are widely acknowledged. In a 1998 report, the Institute of Medicine identified inadequate education and training of clinicians as a key problem with quality of healthcare in the USA (9), with between 44,000 and 98,000 human deaths being attributed yearly to medical error, adding an estimated $\$ 29$ billion to the annual cost of healthcare (10). There is a growing cadre of medical educators who recognise the potential of simulation to ameliorate this problem through improved training and subsequent patient safety. These visionaries recognise that replacing animals (and to some extent cadavers and clinical training) would actually improve training in many cases, because simulation has advantages over "animal models". Similarly, training in the clinical setting (usually, one hopes, under expert supervision) presents problems that are transcended by simulation. Among simulation's advantages are:

- no risk to patients - trainees err on a simulator, not a patient; 
- no risk to trainees (e.g. from exposure to patient blood-borne pathogens);

- opportunity to gain procedural familiarity and comfort through unlimited repetition;

- providing a full range of patient cases including complications, pathologies, and anatomical variants rarely encountered but for which practitioners must be prepared;

- objective measurement of specific skills and procedural competence through case-based and longitudinal data tracking of trainee performance;

- freedom from ethical controversy (no patient consent required, no harm to animals);

- anatomical and physiological realism - animal anatomy differs from human anatomy;

- cadaver tissues handle and respond differently than does living tissue;

— viewing the "patient" in ways impossible during a real surgery (e.g. transparency views; full patient rotation in space; external organ/scope views during endoscopy);

- introducing new procedures to practising surgeons, speeding their adoption;

— training more practitioners in less time, ultimately shortening patient waiting lists;

- stand-alone training not requiring the constant presence of an instructor;

— selection of content to focus on areas of greatest need for improvement;

- facilitating learner self-monitoring, and assessment by instructors;

- long-term cost savings compared to animal use (see below); and

- potential to dramatically lower costs through improved clinical outcomes.

These benefits are not going unnoticed. As of July 2001, 19 trauma training sites in the USA are known to be using exclusively non-animal methods - predominantly simulators and human cadavers (11). In 2001, the American College of Surgeons Committee on Trauma approved for the first time the use of anatomical human simulators in place of live animals to teach advanced trauma life support (ATLS). The Simulab
Trauma Man ${ }^{\circledR}$ surgical trainer, an HPS designed to teach surgical procedures, including open and catheter DPL, chest tube insertion, pericardiocentesis and cricothyroidotomy, is one of the first simulators to be approved to teach entire ATLS courses (5).

\section{Empirical results}

Stating perceived benefits is much easier than demonstrating them. Due mainly to their relatively recent appearance on the medical education stage, there are only a modest number of studies evaluating the performance and efficacy of commercialised simulators. The most studied to date are those of Immersion Medical (Table $1)$.

In summary, studies of Immersion Medical simulators have shown that they measure what they are intended to (20), that they discriminate users based on procedural experience $(12,14,15,17,20)$ and that they significantly improve practitioner performance $(13,16,18,20)$.

A recent study conducted at the Mayo Clinic concluded that Immersion's colonoscopy simulator would be most beneficial in the early stages of training for the procedure (21). Trainees at the Mayo Clinic must now complete nine hours of simulator training involving approximately 25 virtual procedures, then demonstrate certain performance standards on the simulator before advancing to live-patient colonoscopies. Another study reported significant improvements in procedural competence (shorter duration, improved hand-eye skill, more thorough visualisation) for medical residents $(\mathrm{n}=5)$ who trained for six hours on a VRS for flexible sigmoidoscopy compared with residents $(n=5)$ who did not use the simulator (22).

The latest in HPSs are also yielding positive results. An evaluation of the METI HPS compared the performance of teams of ATLS students with that of teams of experienced emergency surgeons (23). All student teams demonstrated improvement in all five tasks scored and on six of eight timed tasks. Latter performance by the student teams approached that of the expert teams. Construct validity for an HPS (Eagle Simulation) was demonstrated on six of ten metrics in discriminating experienced clinicians $(\mathrm{n}=17)$ from medical residents $(n=8)$ in performing anaesthesia-related procedures (24). A study of the MIST VR simulator (now part of Mentice Corp.) for evaluating laparoscopic surgical skills found that students' performance on the simulator correlated significantly with their performance on an animal (pig; 25). This study assumes, perhaps falsely, that procedural skill on a pig correlates with that on a human. 


\section{Costs}

Though simulators are not cheap, for a host of reasons their costs in the long-term are lower than the cumulative costs of using animals. Animal labs require licensed animal caretakers, housing, veterinary care, anaesthesia, and the disposal of hazardous wastes. Institutional animal care and use committee members must also spend time assessing, modifying and approving (or denying) submit- ted protocols. As a case in point, the Surgical Research Laboratory at Rush Presbyterian St Lukes Hospital uses several hundred dogs and about 100 pigs per year in its medical training programmes. The costs per each animal exceed $\$ 650$ (M. Haklin, personal communication, August 2002). Immersion's AccuTouch Endoscopy system currently retails in the range of $\$ 35,000-40,000$.

In addition to their potential for long-term savings over learning resources that require continual

Table 1: Published evaluations of Immersion Medical training simulators

\begin{tabular}{|c|c|c|c|}
\hline Authors & Simulator & Study subjects & Principal findings \\
\hline $\begin{array}{l}\text { Britt et al. } \\
1998 \text { (12) }\end{array}$ & $\begin{array}{l}\text { Immersion Medical, } \\
\text { flexible bronchoscopy }\end{array}$ & $\begin{array}{l}15 \text { bronchoscopists: } \\
3 \text { novices, } 7 \text { experts, } \\
5 \text { intermediates }\end{array}$ & $\begin{array}{l}\text { Simulator differentiated three user groups } \\
\text { according to procedure duration: beginners } \\
\text { longest, experts shortest, and intermediates } \\
\text { medium times }\end{array}$ \\
\hline
\end{tabular}

\begin{tabular}{|c|c|c|c|}
\hline $\begin{array}{l}\text { Colt et al. } \\
2001 \text { (13) }\end{array}$ & $\begin{array}{l}\text { Immersion Medical, } \\
\text { flexible bronchoscopy }\end{array}$ & $\begin{array}{l}9 \text { bronchoscopists: } \\
5 \text { novices, } 4 \text { highly skilled }\end{array}$ & $\begin{array}{l}\text { After simulator training, novices performed } \\
\text { simulated bronchoscopies as well or better } \\
\text { than did experts }\end{array}$ \\
\hline
\end{tabular}

\begin{tabular}{|c|c|c|c|}
\hline $\begin{array}{l}\text { Datta et al. } \\
2002(14)\end{array}$ & $\begin{array}{l}\text { Immersion Medical, } \\
\text { flexible sigmoidoscopy }\end{array}$ & $\begin{array}{l}45 \text { endoscopists: } \\
15 \text { novices, } 15 \text { experts, } \\
15 \text { intermediates }\end{array}$ & $\begin{array}{l}\text { Simulator differentiated procedural } \\
\text { performance (procedure time, \% mucosa } \\
\text { visualised, and efficiency ratio [\% mucosa/ } \\
\text { time]) according to user experience }\end{array}$ \\
\hline
\end{tabular}

\begin{tabular}{|c|c|c|c|}
\hline $\begin{array}{l}\text { Mehta et al. } \\
2000 \text { (15) }\end{array}$ & $\begin{array}{l}\text { Immersion Medical, } \\
\text { flexible bronchoscopy }\end{array}$ & $\begin{array}{l}27 \text { bronchoscopists: } \\
9 \text { novices, } 11 \text { experts, } \\
7 \text { intermediates }\end{array}$ & $\begin{array}{l}\text { Simulator differentiated procedural } \\
\text { performance (duration, time in red-out, } \\
\text { scope collisions) according to user } \\
\text { experience }\end{array}$ \\
\hline
\end{tabular}

Ost et al. Immersion Medical, $\quad 6$ first-year pulmonary 2001 (16) flexible bronchoscopy fellows (two randomised groups of 3 each)
Fellows trained on the simulator did better in real bronchoscopies (duration, quality score, nurse score, drug use) than did fellows who had conventional training

$\begin{array}{lll}\text { Rawn et al. } & \text { Immersion Medical, } & 85 \text { caregivers: } \\ 2002(17) & \text { intravenous insertion } & 41 \text { physicians, } \\ & \text { simulator } & 44 \text { nurses }\end{array}$

Rawn et al. simulator

Rowe \& Cohen Immersion Medical, 2000 (18) flexible bronchoscopy

12 anaesthesia residents
Expert physicians out-performed intermediates and novices for 5 of 10 simulator metrics. Expert nurses out-performed intermediates and novices on two metrics
Rowe 2000 (19)
Immersion Medical, flexible bronchoscopy (intubation module)
Subjects improved significantly on real bronchoscopies (shorter duration, less time lost, fewer collisions, less help from attending) after simulator training
Subjects performed live bronchoscopic intubation in less than 90 seconds following training on the simulator (untrained novices usually take $>5$ minutes)

$\begin{array}{lll}\text { Wong et al. } & \text { Immersion Medical, } & 32 \text { vascular surgeons: } \\ 2001(20) & \text { endovascular simulator } & 10 \text { experienced, } \\ & & 12 \text { less experienced, } \\ & 10 \text { no experience }\end{array}$

Simulator differentiated procedural efficiency (shorter duration, better visualisation of tissues) according to user experience 
replacement, simulators also have the potential to pay for themselves in a relatively short time by reducing practitioner error. For example, an estimated 200,000 catheter-related blood stream infections occur yearly in the USA, resulting in increased morbidity and mortality rates of $10-20 \%$, prolonged hospitalisation (average seven days) and increased medical costs in excess of $\$ 6,000$ (1988 figure) per hospitalisation (26). If a teaching hospital that invested in Immersion's CathSim Adult IV module (price range $\$ 8500-10,700$ ) and then training on the device were to prevent just one blood stream infection over its life-time, the device would have nearly paid for itself.

A recent analysis estimated that if clinicians trained on CathSim were able to avert complications in $10 \%$ of clinical cases, institutional savings at an average-sized (100 bed) hospital would range between $\$ 11,700$ (if all events were simple needle insertions) and $\$ 234,000$ (if all involved catheterisations; 27). As no data are yet available to assess actual cost savings from using simulators, these figures remain hypothetical, but a recent study of CathSim suggests that a $10 \%$ or greater improvement of procedural skill through simulator training is a reasonable expectation (17).

Sales of commercial simulators indicate that they are increasingly perceived to be cost-effective. Since release of its first commercial simulator (CathSim: Adult IV) in April 1998, over 750 of Immersion Medical's full simulators have been sold and installed at over 450 facilities worldwide, plus nearly 500 units of its haptic force-feedback laparoscopy devices and engines.

\section{Looking Ahead}

The use of medical simulation is expected to continue growing. As new MIS procedures are devised, interest in developing simulators to train for them grows. A good example is endovascular abdominal aortic aneurysm (AAA) repair, which took a significant step forward in 1999, when the US Food and Drug Administration (FDA) approved two stent graft devices (AneuRx ${ }^{\circledR}$ from Medtronic and Ancure ${ }^{\circledR}$ from Guidant) for clinical use. Today, AAA stent grafting is increasingly offered as a first choice over conventional surgery. Yet, despite certain advantages over conventional AAA repair, complication rates remain high, and the clinical status of AAA stent grafting remains uncertain a decade after its first being performed on a human patient. It is believed that these problems are largely iatrogenic, and that simulationbased training would do much to alleviate them. Immersion Medical has been developing a training simulator for the procedure with funding from the National Institutes of Health.

Simulators promise to significantly improve the certification process. All physicians must obtain certification before they are permitted to perform specific procedures. Currently, US physicians are "Board Certified" by taking a written and oral exam. Motor skills and manual dexterity are not tested. Simulators could greatly strengthen this process by allowing licensing boards and hospital credentialing committees to gather objective data on physicians' ability to perform specific procedures. As data supporting the effectiveness of simulators accumulate, it seems likely that their adoption into the certification process will follow. There are already signs of this happening. Before being dismantled in 2001, due to budgetary cutbacks, the Institute for Clinical Evaluation was being funded to conduct a study of the use of simulators in physician certification.

Another likely future application of simulation to medicine is pre-surgical rehearsal. Among the projects being funded by the European Union's Information Society Technologies programme is a computerised simulation for pre-operative planning, performance and training of surgical procedures. The Integrated Environment for the Rehearsal and Planning of Surgical Interventions (IERAPSI) project aims to allow the download and manipulation of patient specific visual data (instead of generic anatomical data), thereby permitting the planning of surgical interventions that are tailored to each patient. For example, a surgeon can now view, rotate and examine a glistening, six-foot virtual liver on a screen to assess, for example, the extent of a tumor (28). Project Deputy Director, Dr Nigel John, predicts that this technology will become commercially available in the next three to five years. It is further hoped that refinements in the technology will allow surgeons to practise excising the growth with a virtual scalpel. Another benefit of patientspecific simulation is that it will facilitate new surgical approaches to patient problems.

\section{Conclusions}

Medical simulators have the potential to revolutionise medical training and certification practices and to greatly reduce or ultimately eliminate animal use. They deliver many advantages over traditional training methods. Empirical evidence is mounting that they can enhance the acquisition of procedural skills. Their costs are competitive with those of animal-based training, and their administrative and logistical burdens are far lighter. Human healthcare needs and costs can be expected to rise for the foreseeable future. These trends demand less costly, more efficient and more rigorous methods of training, maintaining and assessing practical knowledge and psychomotor skills. By meeting these demands, simulators can simultaneously benefit human healthcare and spare animal lives. 


\section{References}

1. Coppa, G.F. \& Nachbar, M.S. (1997). Virtual reality: an alternative to animal use? In Animal Alternatives, Welfare and Ethics (ed. L.F.M. van Zutphen \& M. Balls), pp. 449-453. New York, NY, USA: Elsevier Science.

2. Empkie, T.W. (1987). Another exciting use for the cantaloupe. Family Medicine 19, 430.

3. Nelson, D.B., Bosco, J.J., Curtis, W.D., Faigel, D.O., Kelsey, P.B., Leung, J.W., Mills, M.R., Smith, P., Tarnasky, P.R., VanDam, J., Wang, K.K. \& Wassef, W.Y. (2000). Technology status evaluation report: endoscopy simulators. Gastrointestinal Endoscopy 51, 790-792.

4. Drone, J. (1999). New directions for medical education. Good Medicine Autumn, 14.

5. Kuhn, K. (2001). Trauma training: Physicians choose nonanimal alternatives. Good Medicine Summer, 6-7.

6. Greek, C.R. \& Greek J.S. (2000). Sacred Cows and Golden Geese: The Human Cost of Experiments on Animals. New York, NY, USA: Continuum International.

7. Siegel, J.H. \& Korsten, M.A. (1989). ERCP in a nonhuman primate. Gastrointestinal Endoscopy 35, 557-559.

8. Hochberger, J., Neumann, M., Maiss, J., Hohenberger, W. \& Hahn, E.G. (1998). EASIE-Erlangen Active Simulator for Interventional Endoscopy - a new bio-simulation model - first experience gained in training workshops. Gastrointestinal Endoscopy 47, AB116.

9. Chassin, M.R., Galvin, R., and The National Roundtable on Health Care Quality (1998). Consensus statement. The urgent need to improve health care quality. Journal of the American Medical Association 280, 1000-1005.

10. Kohn, L.T., Corrigan, J.M. \& Donaldson, M.S. (eds) (1999). To Err is Human: Building a Safer Health System. Washington, DC, USA: National Academy Press.

11. Kuhn, K. (2002). Modernizing trauma training for emergency doctors. Good Medicine Spring-Summer, 6.

12. Britt, E.J., Tasto, J.L. \& Merril, G.L. (1998). Assessing competence in bronchoscopy by use of a virtual reality simulator (abstract). In Program and Abstracts of the Jubilee 10th World Congress for Bronchology \& 10th World Congress for Bronchoesophagology, p. 90. Budapest, Hungary.

13. Colt, H.G., Crawford, S.W. \& Galbraith, O. (2001). Virtual reality bronchoscopy simulation: A revolution in procedural training. CHEST 120, 1333-1339.

14. Datta, V.K., Mandalia, M., Mackay, S.D. \& Darzi, A. (2002). The PreOp flexible sigmoidoscopy trainer: validation and early evaluation of a virtual realitybased system. Surgical Endoscopy 16, 1459-1463.
15. Mehta, A.C., Ost, D., Salinas, S.G., Sanchez, D.E., DeRosiers, A., Tasto, J.L. \& Britt, E. (2000). Objective assessment of bronchoscopy skills by a bronchoscopy training simulator. American Journal of Respiratory and Critical Care Medicine 161, A234.

16. Ost, D., DeRosiers, A., Britt, E., Fein, A.M., Lesser, M.L. \& Mehta, A.C. (2001). Assessment of a bronchoscopy simulator. American Journal of Respiratory and Critical Care Medicine 164, 2248-2265.

17. Rawn, C.L., Reznek, M.A., Heinrichs, W.L., Srivastava, S., Dev, P. \& Drummel, T.M. (2002). Validation of an IV insertion simulator: establishing a standard simulator evaluation protocol. In Conference Proeedings: Medicine Meets Virtual Reality. Newport Beach, USA: Aligned Management Associates, Inc.

18. Rowe, R. \& Cohen, R. (2000). Virtual reality bronchoscopy simulator (abstract). Anesthesiology 93, A1219.

19. Rowe, R. (2000). Time evaluation of a virtual reality bronchoscopy simulator (abstract). Anesthesiology. 93, A-1220.

20. Wong, T., Darzi, A., Foale, R. \& Schilling, R.J. (2001). Virtual reality permanent pacing: Validation of a novel computerized permanent pacemaker implantation simulator. Journal of the American College of Cardiology (Supplement) 37, 493A-494A.

21. Sedlack, R.E. \& Kolars, J.C. (2002). Colonoscopy curriculum development and performance-based assessment criteria on a computer-based endoscopy simulator. Academic Medicine 77, 750-751.

22. Tuggy, M.L. (1998). Virtual reality flexible sigmoidoscopy simulator training: impact on resident performance. Journal of the American Board of Family Practice 11, 426-433.

23. Dumire, R.D., Crommett, J.W. \& Holcomb, J.B. (2002). Evaluation of trauma team performance using an advanced human patient simulator for resuscitation training. Interservice/Industry, Simulation and Education Conference (ITSEC), Orlando, FL, USA.

24. Devitt, J.H., Kurrek, M.M., Cohen, M.M., Fish, K., Fish, P., Noel, A.G. \& Szalai, J-P. (1998). Testing internal consistency and construct validity during evaluation of performance in a patient simulator. Anesthesia and Analgesia 86, 1160-1164.

25. Grantcharov, T.P., Rosenberg, J., Pahle, E. \& Funch-Jensen, P. (2001). Virtual reality computer simulation. Surgical Endoscopy 15, 242-244.

26. Pearson, M.L. (1995). Guideline for Prevention of Intravascular Device-related Infections. Atlanta, GA, USA; National Center for Infectious Diseases, Centers for Disease Control and Prevention.

27. Hanchett, M. (2002). Training simulators for IV education: benefits, costs and new opportunities. Journal of Vascular Access Devices 7, 38-41.

28. Pearson, H. (2002). 3D liver aids surgery. Nature News Service, 11 March. www.nature.com/nsu/ 020304/020304-12.html. 